\title{
Mathematics concept teaching strategy under the background of new

\author{
curriculum and the practice
}

\section{Qingquan Wei}

\section{School of Mathematical Sciences, Liaocheng University, Liaocheng second middle school, Shandong, 252000}

Keywords: A history of mathematics, the use of enhanced understanding of the concept

\begin{abstract}
The high school mathematics curriculum standard" pointed out: in the high school mathematics teaching, we should pay attention to strengthen the understanding of basic concept and basic thought method and master. Of some core concept and basic thought methods throughout the course of the high school mathematics teaching to help students step by step to deepen understanding. New curriculum concept also pointed out that: high school mathematics curriculum should nature, efforts to reveal the development of the mathematical concept, rule, the conclusion and the nature. Mathematics curriculum to logical reasoning, therefore, should be more reasonable, through the analysis of typical examples and students independent exploration, make students understand math concepts and conclusion, the process of gradually formed the thinking method of experience contain among them, to pursue the development of mathematics history, convert the academic form of mathematics for students to accept education form. Concept teaching as the core of mathematics classroom teaching, must carry out the new teaching idea, causes the student to participate in a meaningful, both fresh produce mathematical concept, essence and deep understanding of the concept of formal, this is the basic mathematics concept teaching strategy. The author based on years of teaching practice, think mathematics concept teaching should grasp the following strategy.

Curriculum emphasizes to clear the cause and effect of mathematical concepts, the introduction of the origin and development process of mathematical concept can stimulate interest in learning. And the history of mathematics teachers feel examination didn't test, although at that time to activate the classroom, but in math class "story telling" seems to be wrong, can have the effect of real suspect, let the students to do more than a few problem is smooth, in the process of problem solving to deepen the understanding of mathematical concepts. This idea has certain representativeness, for a long time to the influence of the exam-oriented education, teachers and students to drown in a stream, don't even know some basic mathematical history. Actually practice alone will not solve all problems, students also can't rely on problem solving and automatically achieve the understanding of mathematical concepts, properly introduce some mathematical concept of the origin and development of history of mathematics knowledge for students to understand concepts can have the effect of practice is not.

"Limit" concept, for example, although high school does not require students to learn, but in "derivative" chapter, this is the necessary knowledge, while students tend to be affected by daily life experience, many people will think "limit" is the "reach", many students are doing a lot of geometric series summation of infinite recursion shrinkage is still not clear after the title of the obtained S value is approximate or accurate value, and even a lot of students in university to study calculus, still doubt the integral area is accurate values. If direct tell students like this (use) limit
\end{abstract}


thought S value is accurately calculated, the student can only is learning and I do not know why, just quickly swallow it, so will not conducive to students mastery of knowledge.

To make students more easily grasp the concept of "limit", teachers can introduce mathematics history knowledge related to the limit, limit is a very important mathematical thought, that the extreme thought makes the whole mathematics really be mathematics. As early as the 3rd century Chinese mathematician Liu Hui pioneered "cyclotomic surgery", it is using the ideas of limit, calculate the P, namely "emblem ratio"; In ancient Greece, of circular area AnDiFeng "method of exhaustion," Archimedes successfully with the method of exhaustion and out of the area. Later, under the guidance of limit thought, through the efforts of several generations, people set up strict calculus theory, function theory, and a variety of geometry. Through the interpretation of this, students will naturally understand daily life "limit" and "limit" of mathematics are very different things. At the same time, through the interpretation of the history of mathematics can help students deepen the understanding of concepts, stimulate interest in learning. $\circ$

In studying the concept of sequence, for example, first class open your books to see the introduction, because of the introduction of the story is both interesting and also contains the wisdom, is growing point of learning interest, is a learning content of catalyst. On the basis of the reading of the mathematics problem are derived, which chess inventor requirements per case of wheat was in the number is, the king $2,,, \ldots$, . These constitute a number of columns; Let students think again, how many times a piece of paper can be repeated folded, please try the students take a piece of paper, then the area of the paper (a paper of the original area of 1 unit of area) is $1,,, \ldots,, \ldots$ Composed of a number of columns; And then teachers series around some examples, such as the classes of student number $1,2,3,4, \ldots$ Composition, 52, a number of columns; A radioactive element each after a year, the remaining amount is $84 \%$, the amount of remaining 1,0.84 every year, $0.842,0.843, \ldots$ Also make up the number of columns, again from the above four find out the common characteristics in the number of columns, abstracts the concept of the sequence.

As another example, in the "reduction to absurdity" lesson teaching, I'll let students read the story of the roadside lee bitter: cauley seven years old, and taste and all the children to swim. See roadside plum tree breed broken branches, and the son walking back, but to Dijon. People ask, answer yue: "tree in the roadside and fertility, a bitter lee." Take the letter. Then elaborate its reasoning process: if the plum is sweet, early are lighting. Here, "plum tree breed fold branch" is a condition, "li" is a conclusion. Students after the above process, the text not only to the evidence that the steps have a clear understanding of, but also through the process of the concept of occurrence and development.

Again, such as design example for concept, namely, in the form of specific image to make the students come into contact with the new concept from the instance. Speak such as elliptic back, the teacher can take a no elastic rope, with chalk on the blackboard points less than the cord length, distance between two points in two students, please each hold the rope end on these two points, one student a piece of chalk to pull the rope tight, then move the chalk The rope has been taut, thus draw an ellipse, which leads to its definition And hyperbola, parabola and other concepts can also be lead by way of intuitive presentation. Attention because of the specific vividly introduced the concept of the process of teaching concept, for this contains abundant mathematical thought and method in the process of the necessary of digging, plus students personally involved in the formation of the concept, to activate students' learning enthusiasm and initiative, subjectively to reduce teaching difficulty. 


\section{From Analyze the Introduction to the Key Words, Help Students to Master Math Concepts Accurately}

In general, every concept of the definition of mathematics, always use the most concise language, symbol expression, gives the concept, if we can guide students to seriously analyze the concept, to understand the concept will play a very important role. discussing the symmetry of the quadratic function, parity, monotonicity.

Being displayed visually through the image, and personally participate in operation by the students, to explore cooperation, to help students deepen the understanding of concepts and grasp, truly grasp the concept of the essence.

\section{With the help of other disciplines of knowledge contribute to understanding of the concept}

In the process of concept learning, pay attention to the relationship and difference between the concept and concept, can broaden the students way of thinking, and gradually form the students about things and things are interconnected between the dialectical materialist point of view. Concept teaching, use the method of analogy, the concept of nature, with the most concentrated, the most clear form, make the person be clear at a glance, clarify the understanding of the concept of fuzzy, to distinguish easily confused concept, a correct understanding and application of the concept.

As another example, in learning plane vector and space vector, we can use the method of analogy directly from $2 \mathrm{~d}$ to $3 \mathrm{~d}$ space space of knowledge transfer, we can directly by the "fundamental theorem of plane vector" analogy "fundamental theorem of space vector; Can directly by the "plane vector coordinate and its computing" analogy "space vector coordinates and operation" and so on, so the relevant knowledge into a let students understand, easier to let the students to accept new knowledge.

Nine, through reasonable practice deepen the understanding of the concept

There is no denying that students want to deep understanding of math concepts cannot be separated from practice. Many mathematical concept itself has duality and is characterized by a process operation, and show the object structure. As a kind of operating practice practice is to understand the steps necessary to math concepts. More importantly, a certain amount of practice provides students with the possibility of reflection and comprehension, and this kind of reflection and comprehension is an indispensable part of the students further understand the concept. But the effect of practice but not blindly exaggerated, we must oppose that blindly, mechanical, and attempt to pump type of practice, to scientifically and rationally according to the students' cognitive law practice.

Also, such as, students' positive and inverse function, can remember the definition and analytical form, does not seem to is out of question. But for the topic: set, and become direct ratio, and inversely proportional, and when; The value of,,,.

The student union,,. , after generations come to find that left a condition not used. When the students through the analysis to further understand, and positively with proportion, and the proportion of inversely proportional coefficient does not necessarily equal, well realize the education goal, ontology should be set up

In view of the weak link design purposeful practice students, through to the error correcting, let the students to break through the concept from the opposite side.

Step 2 because any a definition of FFT is a true proposition, choose a topic of nature need to apply the monotonic function solutions, reverse use concept; 
Step 3 further the properties of the flexible use of monotone function problem solving, choose to have certain difficulty comprehensive topic;

Fourth level need to construct the monotonic function to solve problems, cultivate creative thinking. Through hierarchical practice to deepen the understanding of mathematical concepts.

High school mathematics curriculum proposed to understand the basic idea of "double-base", concept teaching is an important part of the "double base" teaching, so, through the mathematics concept teaching, make students to understand concepts, understand the concept, reinforce concepts, is the fundamental aim of mathematics concept teaching. Through the teaching concept, and strive to make students clear: (1) the concept of the occurrence, development process and background; (2) what are the rules and limitation in concept, they are associated with previous knowledge of what; (3) what is the name, description of the concept of language characteristic; (4) concepts have equivalent description; Use of concepts (5) which can solve mathematical problems, etc.

In short, study mathematics concept teaching way, the innovation of mathematics concept teaching method, make students understand thoroughly firmly grasp the crux of the mathematical concept is to improve the quality of mathematics teaching, a maths teacher should first realize the mathematics concept teaching can help us to strengthen the basic knowledge of mathematics teaching, help students to develop and strengthen the awareness of innovation and application of mathematics, helping students to cultivate space imagination ability and logical thinking. Therefore, in the concept teaching, according to the specific requirements of the standard of concept teaching, creative use of teaching materials, optimizing teaching design concept, grasp the concept of the teaching process, make students produce the inner experience in participating in the process of and creation, the purpose of understanding the nature of mathematical thinking and, to get good teaching result.

\section{Reference}

[1] Chen Zhongcheng. Under the new standard of mathematics concept teaching [J], hainan education publishing house, 2007 edition

[2] zhao-hui liu. The basic requirements of mathematics concept teaching [J]. Journal of hunan education, 1997 (03)

[3] li-ping lu. Basic strategy of optimization mathematical concept teaching. Education in jiangxi province, 2001 (10)

[4] GuHuanChun ZongPeiLei Yu Xingjiang. "cultural viewpoint of modern mathematics curriculum", shandong university press, 2006.8

[5] Liang Huibiao. New teaching material of mathematics concept teaching several practices. Guangdong education, 2004, (05) 